\title{
Semi-quantitative estimates of paleo
}

Arctic sea ice concentration based on source-specific highly branched isoprenoid alkenes: A further development of the PIP25 index

Smik, L

http://hdl.handle.net/10026.1/8171

10.1016/j.orggeochem.2015.12.007

ORGANIC GEOCHEMISTRY

Elsevier BV

All content in PEARL is protected by copyright law. Author manuscripts are made available in accordance with publisher policies. Please cite only the published version using the details provided on the item record or document. In the absence of an open licence (e.g. Creative Commons), permissions for further reuse of content should be sought from the publisher or author. 


\section{Accepted Manuscript}

Semi-quantitative estimates of paleo Arctic sea ice concentration based on source-specific highly branched isoprenoid alkenes: a further development of the $\mathrm{PIP}_{25}$ index

Lukas Smik, Patricia Cabedo-Sanz, Simon T. Belt

PII:

S0146-6380(15)00239-9

DOI: http://dx.doi.org/10.1016/j.orggeochem.2015.12.007

Reference: OG 3348

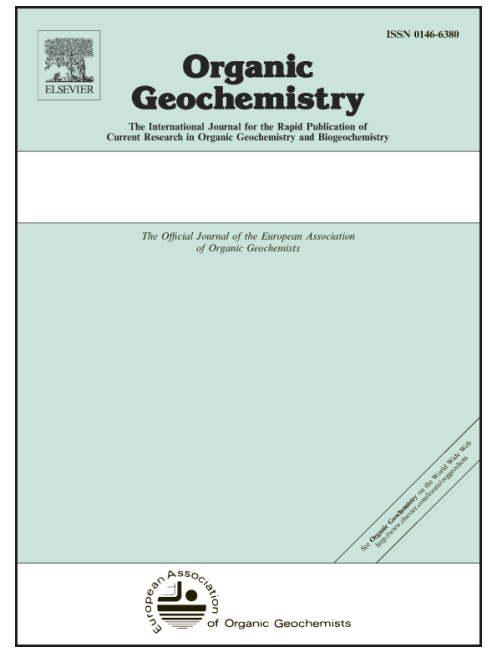

To appear in:

Organic Geochemistry

Received Date: 22 September 2015

Revised Date:

3 December 2015

Accepted Date:

17 December 2015

Please cite this article as: Smik, L., Cabedo-Sanz, P., Belt, S.T., Semi-quantitative estimates of paleo Arctic sea ice concentration based on source-specific highly branched isoprenoid alkenes: a further development of the $\mathrm{PIP}_{25}$ index, Organic Geochemistry (2015), doi: http://dx.doi.org/10.1016/j.orggeochem.2015.12.007

This is a PDF file of an unedited manuscript that has been accepted for publication. As a service to our customers we are providing this early version of the manuscript. The manuscript will undergo copyediting, typesetting, and review of the resulting proof before it is published in its final form. Please note that during the production process errors may be discovered which could affect the content, and all legal disclaimers that apply to the journal pertain. 
Disclaimer: This is a pre-publication version. Readers are recommended to consult the full published version for accuracy and citation.

Semi-quantitative estimates of paleo Arctic sea ice

concentration based on source-specific highly branched

isoprenoid alkenes: a further development of the $\mathrm{PIP}_{25}$

index

Lukas Smik, Patricia Cabedo-Sanz, Simon T. Belt"

School of Geography, Earth and Environmental Sciences, University of

Plymouth, Drake Circus, Plymouth, Devon PL4 8AA, UK

* Corresponding author. Tel.: +44 (0)1752 584959; Fax: +44 (0)1752 584709

E-mail address: sbelt@plymouth.ac.uk (Simon Belt) 


\section{ABSTRACT}

Previously reported concentration data for highly branched isoprenoid (HBI) alkenes and the sterol 24-methylcholesta-5,22E-dien-3 -ol (brassicasterol or epi-brassicasterol) obtained from 45 Barents Sea surface sediments reflecting contrasting sea ice conditions have been combined together in the form of the $\mathrm{PIP}_{25}$ index, with outcomes compared with recent mean decadal satellite-derived spring and summer sea ice concentrations. Reasonably good positive linear relationships were found between $\mathrm{PIP}_{25}$ indices and spring sea ice concentration, with the strongest correlation found when using a tri-unsaturated HBI (HBI III) as the open-water counterpart to the sea ice biomarker $\mathrm{IP}_{25}$, likely as a result of the greater sensitivity and selectivity of HBI III to the neighbouring sea ice conditions compared to epibrassicasterol. The quality of the linear fits between $\mathrm{P}_{\mathrm{III}} \mathrm{IP}_{25}$ (i.e., $\mathrm{PIP}_{25}$ based on HBI III) and spring sea ice concentration together with their respective spatial distributions were also far less dependent on the balance factor $c$, than for $\mathrm{P}_{\mathrm{B}} \mathrm{IP}_{25}$ (i.e., $\mathrm{PIP}_{25}$ based on epi-brassicasterol), which may have important positive consequences for down-core semi-quantitative sea ice reconstruction, and when making comparisons between outcomes from different Arctic regions or climatic epochs. In contrast, consistently weak linear relationships were observed between individual biomarkers and spring or summer sea ice concentration, and between $\mathrm{PIP}_{25}$ values and summer sea ice concentration. However, we provide evidence that a lower limit threshold for $\mathrm{P}_{\mathrm{III}} \mathrm{IP}_{25}$ might represent a useful qualitative proxy for the 
Disclaimer: This is a pre-publication version. Readers are recommended to consult the full published version for accuracy and citation.

past occurrence of summer sea ice. Surface sediment biomarker data from other regions will be needed before the significance of our findings can be fully evaluated.

Keywords: Sea ice; highly branched isoprenoid; $\mathrm{IP}_{25}$; alkenes; sterols;

biomarker; Arctic 
Disclaimer: This is a pre-publication version. Readers are recommended to consult the full published version for accuracy and citation.

\section{Introduction}

In recent years, the mono-unsaturated $\mathrm{C}_{25}$ highly branched isoprenoid (HBI) alkene $\mathrm{IP}_{25}$ (Fig. 1; Belt et al., 2007) has emerged as a particularly useful proxy indicator of past seasonal sea ice occurrence when identified in Arctic and sub-Arctic marine sediments (for a review see Belt and Müller, 2013). Amongst its various attributes, $\mathrm{IP}_{25}$ appears to be made, selectively, by certain diatoms that reside in the underside of Arctic sea ice (Belt et al., 2007, 2013; Brown et al., 2011, 2014) and appears relatively stable in the recent and long-term sedimentary record (Knies et al., 2014). Accordingly, $\mathrm{IP}_{25}$ is commonly found in surface sediments from regions that experience seasonal sea ice cover (Müller et al., 2011; Navarro-Rodriguez et al., 2013; Stoynova et al., 2013; Xiao et al., 2013, 2015a), yet is normally undetected in year-round ice-free marine settings (e.g., Méheust et al., 2013; NavarroRodriguez et al., 2013).

Directional changes in down-core sedimentary $\mathrm{IP}_{25}$ concentration are generally consistent with the corresponding temporal shifts in sea ice extent (e.g., Massé et al., 2008; Vare et al., 2009; Fahl and Stein, 2012; Müller et al., 2012; Knies et al., 2014), although absolute abundances exhibit a large regional variability for otherwise similar sea ice concentrations (Stoynova et al., 2013). In addition, although it has been suggested that the absence of $\mathrm{IP}_{25}$ may reflect either ice-free or permanent sea ice conditions (Belt et al., 2007; Müller et al., 2011), this biomarker has, in fact, been identified in a 
small number of sediments from year-round open ocean locations (NavarroRodriguez et al., 2013) and, most recently, in high Arctic sediments corresponding to regions with near perennial ice cover (Xiao et al., 2015a). In any case, in order to improve on the qualitative aspects of $\mathrm{IP}_{25}$-based measurements, Müller et al. (2009) first suggested that, in cases with absent $\mathrm{IP}_{25}$, the co-measurement of certain phytoplankton biomarkers (e.g., sterols such as epi-brassicasterol or dinosterol) could potentially be used to distinguish between these two extreme environmental settings. Note that we have used the term epi-brassicasterol for 24-methylcholesta-5,22E-dien3 -ol as this is the isomer found in diatoms (Volkman, 1986; Volkman et al., 1998). Indeed, such an approach has been shown to work reasonably well (and consistently) as part of qualitative paleo sea ice determinations for different Arctic regions (e.g., Müller et al., 2009, 2012, 2014; Fahl and Stein, 2012; Cabedo-Sanz et al., 2013; Stein and Fahl, 2013; Knies et al., 2014;

Xiao et al., 2015b).

Subsequently, Müller et al. (2011) demonstrated that $\mathrm{IP}_{25}$ and phytoplankton biomarker $(\mathrm{P})$ concentrations, when combined in the form of the numerical index $\mathrm{PIP}_{25}$ (Eqn. 1), could provide more semi-quantitative estimates of sea ice conditions, at least for Fram Strait/East Greenland, and a number of applications of the $\mathrm{PIP}_{25}$ index have followed (e.g., Fahl and Stein, 2012; Müller et al., 2012, 2014; Cabedo-Sanz et al., 2013; Stein and Fahl, 2013; Berben et al., 2014). An additional feature of the $\mathrm{PIP}_{25}$ index is that its range (0-1, representing a gradient of ice-free to extended sea ice 
cover), means that comparisons between studies are, in theory, more straightforward than with $\mathrm{IP}_{25}$ alone, especially given the large (several orders of magnitude) sedimentary concentration range of the latter (e.g., Stoynova et al., 2013).

$$
\begin{aligned}
& \mathrm{PIP}_{25}=\mathrm{IP}_{25} /\left(\mathrm{IP}_{25}+c \mathrm{P}\right) \\
& c=\text { mean } \mathrm{IP}_{25} / \text { mean } \mathrm{P}
\end{aligned}
$$

Despite this development, however, a number of factors still need to be better understood before the general applicability of the $\mathrm{PIP}_{25}$ approach can be established (Belt and Müller, 2013; Xiao et al., 2015a) including: (i) identification of the most suitable open-water (pelagic) biomarker as a counterpart to $\mathrm{IP}_{25}$; (ii) the possible impacts of additional (non-marine) sources to the pelagic biomarker budget; (iii) the consequences of variability within the so-called balance factor ( $c$ in Eqn.1) used in the $\mathrm{PIP}_{25}$ calculation. For example, according to the original model presented by Müller al. (2011), the phytoplankton marker should ideally provide a representative and consistent response to the proximal sea ice conditions and have a selective marine origin. In practice, the most appropriate phytoplankton marker for $\mathrm{PIP}_{25}$-based sea ice concentration estimates has been shown to be strongly regionally dependent (Müller et al., 2011; Stoynova et al., 2013; Xiao et al., 2015a), while some sterols may be derived from marine and non-marine sources (e.g., Huang and Meinschein, 1976; Volkman, 1986). The inclusion 
of the $c$ term was originally introduced by Müller et al. (2011) to compensate for the generally significantly higher sedimentary concentrations of pelagic biomarkers compared to $\mathrm{IP}_{25}$. In the absence of an established fixed value for $c$ (global or regional), this balance factor is derived from the relative mean concentration of each biomarker (Eqn. 2) within a suite of surface or downcore sediments pertinent to the individual spatial or temporal study, respectively. However, this piecemeal mode of calculation can lead to problems in both cases. For down-core records, the magnitude of $c$ can be strongly dependent on the nature of the temporal window of the core being studied (e.g., ice-covered versus ice-free) or, indeed, of any sub-interval (Belt and Müller, 2013; Belt et al., 2015), with consequential impacts on $\mathrm{PIP}_{25}$. As an example, relatively high $\mathrm{PIP}_{25}$ values, interpreted as reflecting extensive sea ice cover, can be modified to low/medium values (low or occasional sea ice) simply by extension of the temporal record to intervals that have higher $\mathrm{IP}_{25}$ content, as can frequently be the case when studying consecutive climatic epochs with contrasting sea ice cover such as the Younger Dryas and the Holocene (e.g., Müller et al., 2009, 2014; Cabedo-Sanz et al., 2013; Belt et al., 2015). For spatial studies, the inclusion of substantial numbers of sediments from ice-free locations clearly impacts on the mean $\mathrm{IP}_{25}$ value, in particular, thus negatively influencing the $c$ term and, therefore, outcomes for regions of seasonal sea ice cover. In addition, supplementing new biomarker data, either within surface sediment-based calibrations or for down-core records, requires continuous re-calculation of the $c$ factor, which 
is not only cumbersome, but makes comparisons of datasets (or sub-sets) virtually impossible. Recently, Xiao et al. (2015a) suggested that a global $c$ factor, derived from biomarker data from a large number of sediments from different Arctic regions, might be more useful in these respects. In practice, however, significant regional differences in $c$ means that selection of the most suitable value remains problematic. Despite these limitations, $\mathrm{PIP}_{25}$ derived estimates of (spring) sea ice concentration are normally better than those based on $\mathrm{IP}_{25}$ alone, so further investigations into this type of approach are certainly worthwhile.

Here, we hypothesised that a tri-unsaturated HBI (HBI III; Fig. 1;

Belt et al., 2000) might represent a more suitable phytoplankton biomarker for use within the $\mathrm{PIP}_{25}$ index than the sterols used currently (i.e., epibrassicasterol, dinosterol) for the following reasons. First, we demonstrated recently that concentrations of $\mathrm{IP}_{25}$ and $\mathrm{HBI} \mathrm{III}$ in surface sediments from seasonally ice-covered locations in the Barents Sea were strongly inversely correlated, with higher abundances of $\mathrm{IP}_{25}$ for regions of extended seasonal sea ice cover, and enhanced HBI III for locations proximal to the winter iceedge or within the marginal ice zone (MIZ) (Belt et al., 2015). As such, the respective responses of $\mathrm{IP}_{25}$ and HBI III aligned particularly well with the original gradient model of biomarker production proposed by Müller et al. (2011) that underpins the ratio-based format of the $\mathrm{PIP}_{25}$ index (Eqn. 1). Thus, Müller et al. (2011) suggested that $\mathrm{PIP}_{25}$ should be high under seasonal sea ice (dominated by high $\mathrm{IP}_{25}$ ), with progressive reduction for 
MIZ conditions (dominated by high $\mathrm{P}$ ) and ultimately zero for open water conditions (absent $\mathrm{IP}_{25}$, high $\mathrm{P}$ ). Second, we noted that, for the same Barents Sea sediments, concentrations of $\mathrm{IP}_{25}$ and HBI III were much closer in magnitude compared to those of $\mathrm{IP}_{25}$ and epi-brassicasterol (Belt et al., 2015), which may go some way to removing (or reducing) the strong influence of the $c$ term in the $\mathrm{PIP}_{25}$ calculation. Third, although the specific sources of HBI III in Barents Sea sediments have not been identified unequivocally, the only known producers of this biomarker are marine diatoms belonging to the genera Pleurosigma and Rhizosolenia (Belt et al., 2000; Rowland et al., 2001), both of which contain planktonic species and, therefore, represent potential candidates for production of HBI III in surface or near-surface waters. Indeed, when measured in marine sediments from other Arctic and Antarctic regions, HBI III has a stable isotopic composition $\left(\delta^{13} \mathrm{C}\right.$ ca. -35 to 40\%o; Belt et al., 2008; Massé et al., 2011) consistent with a polar phytoplanktonic origin (e.g., Belt and Müller, 2013; Massé et al., 2011). Thus, HBI III does not appear to suffer the ambiguity of origin generally associated with 24-methylcholesta-5,22E-dien-3 -ol, for example, which may be derived from marine, terrestrial and sea ice sources (Huang and Meinschein, 1976; Volkman, 1986; Belt et al., 2013).

To test our hypothesis, we re-examined biomarker data from some of the Barents Sea surface sediments by comparing their individual and combined $\left(\mathrm{PIP}_{25}\right)$ relationships to spring and summer sea ice concentration. Our study focused on those locations that experience sea ice cover at least 
part of the year, which corresponds to a region generally north of the position of maximum (spring) sea ice extent. Although biomarker data were also available from ice-free locations (see Belt et al., 2015 for details), we did not include these in our analysis here, in part, since the primary aim was to investigate the potential for different $\mathrm{PIP}_{25}$ indices to provide semiquantitative estimates of sea ice concentration (specifically, sea ice concentration $>0 \%$ ), but also because zero values for both $\mathrm{PIP}_{25}$ and sea ice concentration found for such regions would adversely skew the linear correlations between these two parameters for ice covered settings. Further, since a zero value for $\mathrm{PIP}_{25}$ can only be obtained from the absence of $\mathrm{IP}_{25}$, in any case, no additional information regarding sea ice concentration is gained from this combined approach compared to measurement of $\mathrm{IP}_{25}$ alone. As such, our analysis represents a regional calibration, as defined by locations experiencing sea ice occurrence for at least part of the year (i.e., spring sea ice concentration $>0 \%$ ).

\section{Experimental}

Descriptions of sediment material and biomarker data can be found elsewhere (Navarro-Rodriguez et al., 2013; Belt et al., 2015). In total, sedimentary biomarker data from 45 sample locations, each of which experience seasonal sea ice cover in recent decades (Fig. 2), were used in the analysis. $\mathrm{PIP}_{25}$ indices were calculated according to Eqns. 1 and 2 (Müller et 
Disclaimer: This is a pre-publication version. Readers are recommended to consult the full published version for accuracy and citation.

al., 2011) using HBI III $\left(\mathrm{P}_{\mathrm{III}} \mathrm{IP}_{25}\right)$ and epi-brassicasterol $\left(\mathrm{P}_{\mathrm{B}} \mathrm{IP}_{25}\right)$ as the phytoplankton biomarkers. Additional $\mathrm{P}_{\mathrm{B}} \mathrm{IP}_{25}$ indices were calculated using a global $c$ factor, derived from analysis of data from a large number of surface sediment samples from different Arctic and sub-Arctic regions (Xiao et al., 2015a). PIP $_{25}$ indices were also calculated with exclusion of the $c$ factor (i.e., $c=1$ ). Estimates of mean spring (April-June) and summer (July-September) sea ice concentrations (hereafter referred to as SpSIC and SuSIC, respectively) for the sampling region were obtained from Nimbus-7 SMMR and DMSP SSM/I-SSMIS passive microwave data for the period 1988-2007 (National Snow and Ice Data Center; NSIDC). We selected these data partly because quantitative sea ice data from this interval have been used in the most detailed $\mathrm{PIP}_{25}$-based calibrations to date (Xiao et al., 2015a) and also since a 20-year interval reflects typical accumulation rates for the Barents Sea (see Belt et al., 2015 for further details). Further, Navarro-Rodriguez et al. (2013) stated that satellite-derived mean sea ice concentration data are reasonably consistent between datasets covering recent decades, irrespective of their exact timeframe. Finally, it is noted that, although the position of the maximum winter ice edge in the Barents Sea has undergone a northerly retreat over the last ca. 150 years (Divine and Dick, 2006), all of our selected sampling locations fall within a consistently spring ice-covered region during this time interval, while the excluded sites have always been ice-free. 


\section{Results}

$\mathrm{IP}_{25}$ concentration in Barents Sea surface sediments shows a general increase with SpSIC, although a linear fit between the two is not strong $\left(\mathrm{R}^{2}\right.$ $=0.18$; Fig. $3 \mathrm{a})$, and the relationship to SuSIC is even weaker $\left(\mathrm{R}^{2}<0.01\right.$;

Supplementary Fig. S1). In contrast, HBI III and epi-brassicasterol concentrations exhibit negative relationships with SpSIC (Fig. 3b,c), with a reasonable linear fit for the former $\left(R^{2}=0.66\right)$. No clear relationship exists between either HBI or epi-brassicasterol concentration and SuSIC (Supplementary Fig. S1). PIP $_{25}$ indices for both phytoplankton lipids, calculated according to Eqns. 1 and 2, exhibit good linear relationships with SpSIC (Fig. 4a,c), however, with a particularly strong fit for $\mathrm{P}_{\mathrm{III}} \mathrm{IP}_{25}\left(\mathrm{R}^{2}=0.88\right.$; Fig. 4a). Interestingly, the quality of the fit remains reasonably constant for $\mathrm{P}_{\mathrm{III}} \mathrm{IP}_{25}$ with exclusion of the $c$ factor (i.e., $c=1 ; \mathrm{R}^{2}=0.9$; Fig. $4 \mathrm{~b}$ ), but outcomes for epi-brassicasterol are strongly dependent on the magnitude of c. Thus, an $\mathrm{R}^{2}$ value of 0.71 , based on $\mathrm{P}_{\mathrm{B}} \mathrm{IP}_{25}$ values derived from Eqns. 1 and 2 , reduces to 0.65 and 0.54 using a global $c$ factor (Xiao et al., 2015a), or for $c$ $=1($ Fig. $4 \mathrm{~d}-\mathrm{e})$, respectively. Finally, all PIP $_{25}$ indices show poor linear fits to SuSIC, although all (and only) $\mathrm{P}_{\mathrm{III}} \mathrm{IP}_{25}$ values greater than ca. 0.8 correspond to locations with at least partial summer sea ice cover (> 5\%) (Fig. 5).

\section{Discussion}


SpSIC for the study region study shows a generally northward increase, with approximate ranges of ca. 5-20\%, 20-60\% and 60-100\% for regions ca. $74-76^{\circ} \mathrm{N}, 76-78^{\circ} \mathrm{N}$ and $>78^{\circ} \mathrm{N}$, respectively (Fig. 2a). Following ice retreat during late spring, only locations north of ca. $78^{\circ} \mathrm{N}$ experience some (> 5\%) sea ice cover during the summer months (July-September) with lower concentrations (typically $<50 \%$; Fig. 2b) compared to spring.

The improved linear relationship between $\mathrm{P}_{\mathrm{B}} \mathrm{IP}_{25}$ and SpSIC compared to that obtained using $\mathrm{IP}_{25}$ alone is consistent with observations made previously from other Arctic and sub-Arctic regions (e.g., Müller et al., 2011; Stoynova et al., 2013; Xiao et al., 2013, 2015a). However, on the basis of the data presented here, even further improvements can potentially be obtained by using HBI III as the phytoplankton biomarker when deriving $\mathrm{PIP}_{25}$ indices. At this stage, we suggest that the stronger linear fit between $\mathrm{P}_{\mathrm{III}} \mathrm{IP}_{25}$ and SpSIC may be attributed to a combination of the complementary sensitivities of $\mathrm{IP}_{25}$ and $\mathrm{HBI}$ III to the surrounding sea ice conditions, as demonstrated through the contrasting abundance distributions of these two biomarkers in the same sediments (Belt et al., 2015), together with a greater selectivity of HBI III (compared with epi-brassicasterol) towards a marine phytoplankton origin; both factors aligning well with the underlying principles of the $\mathrm{PIP}_{25}$ approach (see Introduction; Müller et al., 2011). Indeed, Xiao et al. (2015a) recently highlighted the importance of identifying a biomarker of exclusive marine origin for further development of the $\mathrm{PIP}_{25}$ index, especially as biomarkers such as 24-methylcholesta-5,22E-dien-3 -ol 
can originate from a number of other environments (Huang and Meinschein, 1976; Volkman, 1986; Belt et al., 2013), with likely negative impacts on the sedimentary budget.

A further feature of the $\mathrm{P}_{\mathrm{III}} \mathrm{IP}_{25}$ data here is that the calculated range (ca. $0-1$ ), which is virtually identical with exclusion of the $c$ factor, aligns well with the theoretical range (0-1) initially proposed by Müller et al. (2011) for describing different sea ice settings (e.g., ice-free, marginal ice zone, extensive sea ice), and also with the array of sea ice concentrations pertinent to our sampling sites (ca. 5-95\%), with linear fits providing reasonable estimates of low (12-18\%), medium (40-45\%) and high (68-72\%) SpSIC based on $\mathrm{P}_{\mathrm{III}} \mathrm{IP}_{25}$ values of $0.2,0.5$ and 0.8 , respectively. In contrast, in addition to the poorer linear fit that exists between $\mathrm{P}_{\mathrm{B}} \mathrm{IP}_{25}$ and SpSIC (Fig. 4), the range in $\mathrm{P}_{\mathrm{B}} \mathrm{IP}_{25}$ reflecting the extreme limits of sea ice concentration (i.e., $0-100 \%$ ) is extremely sensitive to the magnitude of $c$ (i.e., $0-0.9,0-0.6$ and $0-0.03$ for $c=0.0048,0.023$ and 1 , respectively; Fig. 4c-e) which causes clear difficulties when trying to make comparisons of values between different studies. These outcomes are also illustrated well through visual comparison of various spatial distributions of $\mathrm{PIP}_{25}$ with seasonal sea ice concentration (Fig. 6). For example, and in contrast to the spatial distributions of individual biomarkers (Supplementary Fig. S2), $\mathrm{P}_{\mathrm{III}} \mathrm{IP}_{25}$ data (derived according to Eqns. 1 and 2; Fig. 6c) show an excellent relationship to SpSIC (Fig. 6a), as expected given the strong linear relationship between the two parameters, and the agreement is essentially unaffected following 
removal of the $c$ term (Fig. $6 \mathrm{~d}$ ). In contrast, the spatial distribution of $\mathrm{P}_{\mathrm{B}} \mathrm{IP}_{25}$ shows a generally poorer and less consistent association to SpSIC using each of the three $c$ factors (Fig. 6e-g).

We suggest that the markedly better relationship between $\mathrm{P}_{\mathrm{III}} \mathrm{IP}_{25}$ and SpSIC compared to SuSIC likely reflects the specific or preferred environmental conditions under which each biomarker is biosynthesised, with $\mathrm{IP}_{25}$ being produced by certain sympagic diatoms during the spring algal bloom (Brown et al., 2011; Belt et al., 2013) and HBI III by certain (as yet unknown) phytoplankton that thrive adjacent to the retreating ice edge or MIZ during the late spring melt. Although the latter conclusion is based on the surface sedimentary record (Belt et al., 2015) rather than in situ water column measurements, Smik (personal communication, 2015) recently quantified HBI III in surface waters off East Antarctica and found elevated abundances within the retreating MIZ compared to the adjacent regions of permanently open ocean conditions and extended sea ice cover.

Despite the poor linear relationship between $\mathrm{P}_{\mathrm{III}} \mathrm{IP}_{25}$ and SuSIC (Fig. 5a and b), only values greater than ca. 0.8 are associated with at least partial (> 5\%) summer sea ice cover; a threshold value that might, therefore, provide a useful qualitative indicator of summer sea ice occurrence. A corresponding value is less evident using $\mathrm{P}_{\mathrm{B}} \mathrm{IP}_{25}$ and, further, is highly dependent on the magnitude of $c$ (Fig. 5c-e). Finally, the $\mathrm{P}_{\mathrm{III}} \mathrm{IP}_{25}$ threshold for summer ice occurrence (0.8) is also well demonstrated from a comparison of the spatial $\mathrm{P}_{\mathrm{III}} \mathrm{IP}_{25}$ distribution (Fig. 6c and d) compared to SuSIC (Fig. 6b), 
Disclaimer: This is a pre-publication version. Readers are recommended to consult the full published version for accuracy and citation.

with $\mathrm{P}_{\mathrm{III}} \mathrm{IP}_{25}$ generally $<0.8$ for ice-free regions and values $>0.8$ for those locations further north, and with SuSIC $>0 \%$. Such a binary division is less evident from the $\mathrm{P}_{\mathrm{B}} \mathrm{IP}_{25}$ data, however (Fig. $6 \mathrm{~b}$ and $\mathrm{e}-\mathrm{g}$ ).

The wider scale applicability of our findings will clearly require analysis of surface sediments from other Arctic and sub-Arctic regions, including those that represent potentially different sea ice settings to the consistent advance/retreat cycle that occurs within the Barents Sea. From a local perspective, previous satellite and observational records have shown a retreat in the position of the maximum winter ice edge for the Barents Sea since ca. $1870 \mathrm{AD}$ and a dramatic northward shift in the summer ice edge after ca. 1920 AD (Divine and Dick, 2006). Further sea ice records exist in the form of archived ice charts extending back to the mid- $16^{\text {th }}$ century (ACSYS, 2003), although these are significantly less detailed and frequent compared to the compilations of the last ca. 150 years (Divine and Dick, 2006) and, in any case, such records provide information on ice edge locations rather than spatial assessments of sea ice concentration. Therefore, the regional biomarker $\left(\mathrm{P}_{\mathrm{III}} \mathrm{IP}_{25}\right)$-based calibration described herein provides the necessary background for carrying out longer-term and more detailed estimates of sea ice concentration for the Barents Sea that are not currently available.

\section{Conclusions}


Disclaimer: This is a pre-publication version. Readers are recommended to consult the full published version for accuracy and citation.

Reasonably strong linear relationships between $\mathrm{PIP}_{25}$ indices and SpSIC have been found for biomarker data obtained from 45 surface sediments representing contrasting overlying sea ice settings in the Barents Sea. The linearity between PIP $_{25}$ values and SpSIC was better when using a tri-unsaturated HBI (III) as the phytoplankton marker compared to epibrassicasterol, possibly as a result of a greater sensitivity of the former to the seasonal sea ice conditions, with enhanced production in the MIZ compared to regions of longer lasting sea ice cover. Consistent with the strong linear fit between $\mathrm{P}_{\mathrm{III}} \mathrm{IP}_{25}$ and SpSIC, the spatial distribution of $\mathrm{P}_{\mathrm{III}} \mathrm{IP}_{25}$ exhibited a strong association with the corresponding SpSIC. Since the abundances of $\mathrm{IP}_{25}$ and HBI III were much closer in magnitude than between $\mathrm{IP}_{25}$ and epi-brassicasterol, the linear relationships, range in $\mathrm{PIP}_{25}$ and spatial agreement between $\mathrm{PIP}_{25}$ and SpSIC were also less dependent on the balance factor $c$ for $\mathrm{P}_{\mathrm{III}} \mathrm{IP}_{25}$ than for $\mathrm{P}_{\mathrm{B}} \mathrm{IP}_{25}$. Considerably weaker linear relationships were observed between individual biomarkers and SpSIC or SuSIC, or between PIP $_{25}$ values and SuSIC. However, we provide evidence that a lower limit threshold for $\mathrm{P}_{\mathrm{III}} \mathrm{IP}_{25}$ (ca. 0.8) might represent a useful qualitative proxy for the past occurrence of summer sea ice for the Barents Sea, at least.

\section{Acknowledgments}


Disclaimer: This is a pre-publication version. Readers are recommended to consult the full published version for accuracy and citation.

We thank the University of Plymouth for financial support and Dr

Xiaotong Xiao for assistance with sea ice concentration data. We are

grateful to John Volkman and two anonymous reviewers who provided

useful suggestions for improving the manuscript.

Associate Editor-Philippe Schaeffer 
Disclaimer: This is a pre-publication version. Readers are recommended to consult the full published version for accuracy and citation.

\section{References}

ACSYS, 2003. ACSYS Historical Ice Chart Archive (1553-2002), IACPO Informal Report 8, Arctic Climate System Study, Troms $\varnothing$, Norway. Belt, S.T., Allard, W.G., Massé, G., Robert, J.-M., Rowland, S.J., 2000. Highly branched isoprenoids (HBIs): Identification of the most common and abundant sedimentary isomers. Geochimica et Cosmochimica Acta 64, 3839-3851.

Belt, S.T., Massé, G., Rowland, S.J., Poulin, M., Michel, C., LeBlanc, B., 2007. A novel chemical fossil of palaeo sea ice: $\mathrm{IP}_{25}$. Organic Geochemistry 38, $16-27$.

Belt, S.T., Massé, G., Vare, L.L., Rowland, S.J., Poulin, M., Sicre, M.-A., Sampei, M., Fortier, L., 2008. Distinctive ${ }^{13} \mathrm{C}$ isotopic signature distinguishes a novel sea ice biomarker in Arctic sediments and sediment traps. Marine Chemistry 112, 158-167.

Belt, S.T., Müller, J., 2013. The Arctic sea ice biomarker $\mathrm{IP}_{25}$ : a review of current understanding, recommendations for future research and applications in palaeo sea ice reconstructions. Quaternary Science Reviews 79, 9-25.

Belt, S.T., Brown, T.A., Ringrose, A.E., Cabedo-Sanz, P., Mundy, C.J., Gosselin, M., Poulin, M., 2013. Quantitative measurements of the sea ice diatom biomarker $\mathrm{IP}_{25}$ and sterols in Arctic sea ice and underlying 
Disclaimer: This is a pre-publication version. Readers are recommended to consult the full published version for accuracy and citation.

sediments: Further considerations for palaeo sea ice reconstruction.

Organic Geochemistry 62, 33-45.

Belt, S.T., Cabedo-Sanz, P., Smik, L., Navarro-Rodriguez, A., Berben, S.M.P., Knies, J., Husum, K., 2015. Identification of paleo Arctic winter sea ice limits and the marginal ice zone: optimised biomarker-based reconstructions of late Quaternary Arctic sea ice. Earth and Planetary Science Letters 431, 127-139.

Berben, S.M.P., Husum, K., Cabedo-Sanz, P., Belt, S.T., 2014. Holocene subcentennial evolution of Atlantic water inflow and sea ice distribution in the western Barents Sea. Climate of the Past 10, 181-198.

Brown, T.A., Belt. S., Mundy, C., Philippe, B., Massé, G., Poulin, M., 2011. Temporal and vertical variations of lipid biomarkers during a bottom ice diatom bloom in the Canadian Beaufort Sea: further evidence for the use of the $\mathrm{IP}_{25}$ biomarker as a proxy for spring Arctic sea ice. Polar Biology 34, 1857-1868.

Brown, T.A., Belt, S.T., Tatarek, A., Mundy, C.J., 2014. Source identification of the Arctic sea ice proxy $\mathrm{IP}_{25}$. Nature Communications 5, 4197.

Cabedo-Sanz, P., Belt, S.T., Knies, J.K., Husum, K., 2013. Identification of contrasting seasonal sea ice conditions during the Younger Dryas. Quaternary Science Reviews 79, 74-86.

Divine, D.V., Dick, D., 2006. Historical variability of sea ice edge position in the Nordic Seas. Journal of Geophysical Research 111, C01001. 
Disclaimer: This is a pre-publication version. Readers are recommended to consult the full published version for accuracy and citation.

Fahl, K., Stein, R., 2012. Modern seasonal variability and deglacial/Holocene change of central Arctic Ocean sea-ice cover: New insights from biomarker proxy records. Earth and Planetary Science Letters 351-352, 123-133.

Huang, W.Y., Meinschein W.G., 1976. Sterols as source indicators of organic material in sediments. Geochimica et Cosmochimica Acta 40, 323-330.

Knies, J., Cabedo-Sanz, P., Belt, S.T., Baranwal, S., Fietz, S., Rosell-Melé, A., 2014. The emergence of modern sea ice cover in the Arctic Ocean. Nature Communications 5, 5605.

Massé, G., Rowland, S.J., Sicre, M.-A., Jacob, J., Jansen, E., Belt, S.T., 2008. Abrupt climate changes for Iceland during the last millennium: Evidence from high resolution sea ice reconstructions. Earth and Planetary Science Letters 269, 565-569.

Massé, G., Belt, S.T., Crosta, X., Schmidt, S., Snape, I., Thomas, D.N., Rowland, S.J., 2011. Highly branched isoprenoids as proxies for variable sea ice conditions in the Southern Ocean. Antarctic Science $23,487-498$.

Méheust, M., Fahl, K., Stein, R., 2013. Variability in modern sea-surface temperature, sea ice and terrigenous input in the sub-polar North Pacific and Bering Sea: Reconstruction from biomarker data. Organic Geochemistry 57, 54-64. 
Disclaimer: This is a pre-publication version. Readers are recommended to consult the full published version for accuracy and citation.

Müller, J., Massé, G., Stein, R., Belt, S.T., 2009. Variability of sea-ice conditions in the Fram Strait over the past 30,000 years. Nature Geoscience 2, 772-776.

Müller, J., Wagner, A., Fahl, K., Stein, R., Prange, M., Lohmann, G., 2011. Towards quantitative sea ice reconstructions in the northern North Atlantic: A combined biomarker and numerical modelling approach. Earth and Planetary Science Letters 306, 137-148.

Müller, J., Werner, K., Stein, R., Fahl, K., Moros, M., Jansen, E., 2012. Holocene cooling culminates in sea ice oscillations in Fram Strait. Quaternary Science Reviews 47, 1-14.

Müller, J., Stein, R., 2014. High-resolution record of late glacial sea ice changes in Fram Strait corroborates ice-ocean interactions during abrupt climate shifts. Earth and Planetary Science Letters 403, 446455.

Navarro-Rodriguez, A., Belt, S.T., Brown, T.A., Knies, J., 2013. Mapping recent sea ice conditions in the Barents Sea using the proxy biomarker $\mathrm{IP}_{25}$ : implications for palaeo sea ice reconstructions. Quaternary Science Reviews 79, 26-39.

Rowland, S.J., Allard, W.G., Belt, S.T., Massé, G., Robert, J.-M., Blackburn, S., Frampton, D., Revill, A.T., Volkman, J.K., 2001. Factors influencing the distributions of polyunsaturated terpenoids in the diatom, Rhizosolenia setigera. Phytochemistry 58, 717-728. 
Disclaimer: This is a pre-publication version. Readers are recommended to consult the full published version for accuracy and citation.

Stein, R., Fahl, K., 2013. Biomarker proxy shows potential for studying the entire Quaternary Arctic sea ice history. Organic Geochemistry 55, 98-102.

Stoynova, V., Shanahan, T.M., Hughen, K.A., de Vernal, A., 2013. Insights into circum-Arctic sea ice variability from molecular geochemistry. Quaternary Science Reviews 79, 63-73.

Vare, L.L., Massé, G., Gregory, T.R., Smart, C.W., Belt, S.T., 2009. Sea ice variations in the central Canadian Arctic Archipelago during the Holocene. Quaternary Science Reviews 28, 1354-1366.

Volkman, J.K., 1986. A review of sterol markers for marine and terrigenous organic matter. Organic Geochemistry 9, 83-99.

Volkman, J.K., Barrett, S.M., Blackburn, S.I., Mansour, M.P., Sikes, E.L., Gelin, F., 1998. Microalgal biomarkers: a review of recent research developments. Organic Geochemistry 29, 1163-1179.

Xiao, X., Fahl, K., and Stein, R., 2013. Biomarker distributions in surface sediments from the Kara and Laptev Seas (Arctic Ocean): Indicators for organic-carbon sources and sea-ice coverage. Quaternary Science Reviews 79, 40-52.

Xiao, X., Fahl, K., Müller, J., Stein, R. 2015a. Sea-ice distribution in the modern Arctic Ocean: biomarker records from Trans-Arctic Ocean surface sediments. Geochimica et Cosmochimica Acta 155, 16-29. 
Disclaimer: This is a pre-publication version. Readers are recommended to consult the full published version for accuracy and citation.

Xiao, X., Stein, R., Fahl, K., 2015b. MIS 3 to MIS 1 temporal and LGM spatial variability in Arctic Ocean sea ice cover: Reconstruction from biomarkers. Paleoceanography 30, PA002814. 


\section{Figure captions}

Fig. 1. Structures of HBI biomarkers described in the text: (a) $\mathrm{IP}_{25}$; (b) HBI III.

Fig. 2. Maps of study region with sample locations and mean sea ice concentration for the interval 1988-2007 (NSIDC): (a) Spring (April-June) sea ice concentration (SpSIC); (b) Summer (July-September) sea ice concentration (SuSIC).

Fig. 3. Relationships between individual biomarkers and SpSIC: (a) $\operatorname{IP}_{25}$; (b) HBI III; (c) epi-brassicasterol. $\mathrm{R}^{2}$ values obtained from linear regression fits.

Fig. 4. Relationships between $\mathrm{PIP}_{25}$ indices and SpSIC using different phytoplankton markers and $c$ factors: (a) $\mathrm{P}_{\mathrm{III}} \mathrm{IP}_{25}$; factor calculated from the current biomarker data; (b) $\mathrm{P}_{\mathrm{III}} \mathrm{IP}_{25} ; c=1 ;(\mathrm{c}) \mathrm{P}_{\mathrm{B}} \mathrm{IP}_{25} ; c$ factor calculated from the current biomarker data; (d) $\mathrm{P}_{\mathrm{B}} \mathrm{IP}_{25}$; global $c$ factor as calculated by Xiao et al. (2015a); (e) $\mathrm{P}_{\mathrm{B}} \mathrm{IP}_{25} ; c=1$. $\mathrm{R}^{2}$ values obtained from linear regression fits.

Fig. 5. Relationships between $\mathrm{PIP}_{25}$ indices and SuSIC using different phytoplankton markers and $c$ factors: (a) $\mathrm{P}_{\mathrm{III}} \mathrm{IP}_{25} ; c$ factor calculated from the current biomarker data; (b) $\mathrm{P}_{\mathrm{III}} \mathrm{IP}_{25} ; c=1$; (c) $\mathrm{P}_{\mathrm{B}} \mathrm{IP}_{25} ; c$ factor calculated from the current biomarker data; (d) $\mathrm{P}_{\mathrm{B}} \mathrm{IP}_{25}$; global $c$ factor as calculated by Xiao 
Disclaimer: This is a pre-publication version. Readers are recommended to consult the full published version for accuracy and citation.

et al. (2015a); (e) $\mathrm{P}_{\mathrm{B}} \mathrm{IP}_{25} ; c=1$. A possible threshold $\mathrm{P}_{\mathrm{III}} \mathrm{IP}_{25}$ value (ca. 0.8) for summer sea ice presence $(>5 \%)$ is indicated with a horizontal dotted line.

Fig. 6. Spatial representations of sea ice concentrations and $\mathrm{PIP}_{25}$ indices calculated using different phytoplankton markers and $c$ factors: (a) SpSIC;

(b) SuSIC; (c) $\mathrm{P}_{\text {III }} \mathrm{IP}_{25} ; c$ factor calculated from the current biomarker data; (d) $\mathrm{P}_{\mathrm{III}} \mathrm{IP}_{25} ; c=1 ;(\mathrm{e}) \mathrm{P}_{\mathrm{B}} \mathrm{IP}_{25} ; c$ factor calculated from the current biomarker data; (f) $\mathrm{P}_{\mathrm{B}} \mathrm{IP}_{25}$; global $c$ factor as calculated by Xiao et al. (2015a); (g) $\mathrm{P}_{\mathrm{B}} \mathrm{IP}_{25} ; c=1$. 
Disclaimer: This is a pre-publication version. Readers are recommended to consult the full published version for accuracy and citation.

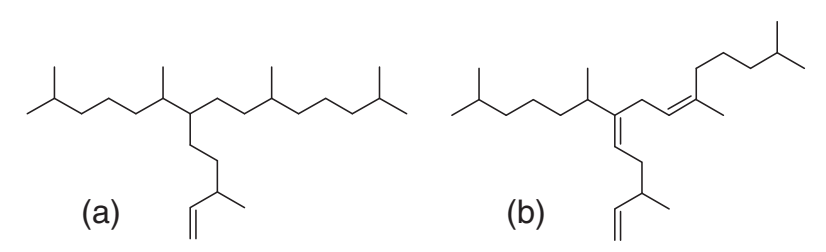


Disclaimer: This is a pre-publication version. Readers are recommended to consult the full published version for accuracy and citation.
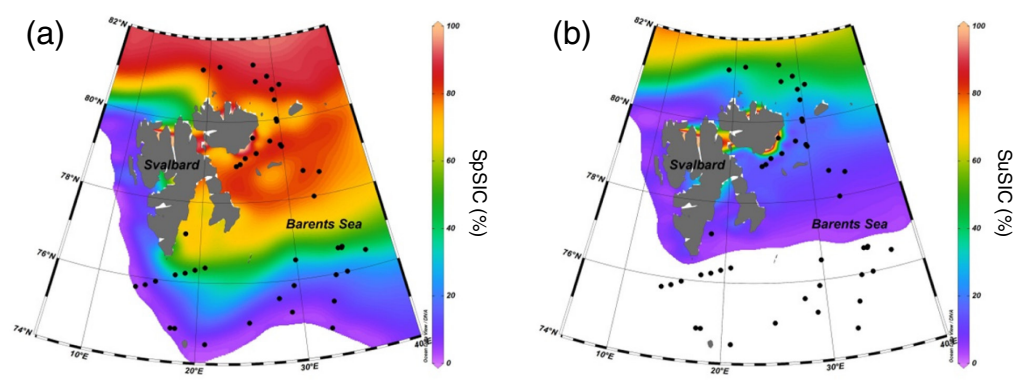
Disclaimer: This is a pre-publication version. Readers are recommended to consult the full published version for accuracy and citation.

Figure 3

(a)

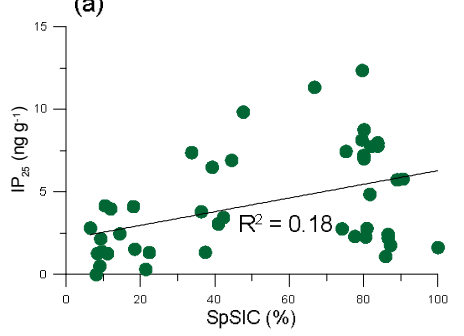

(b)

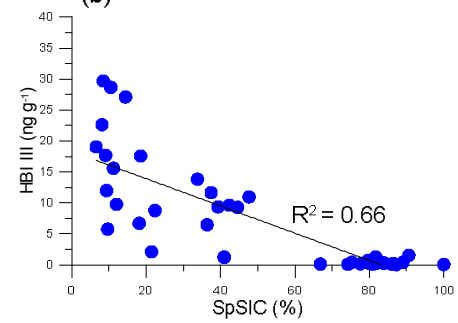

(c)

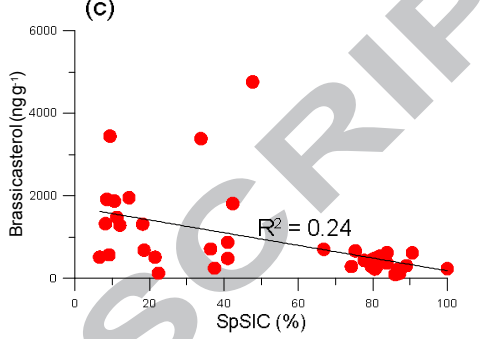

Figure 4
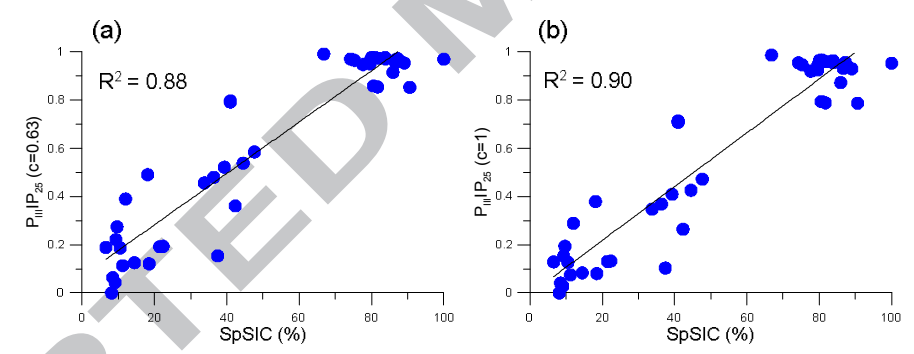

(c)

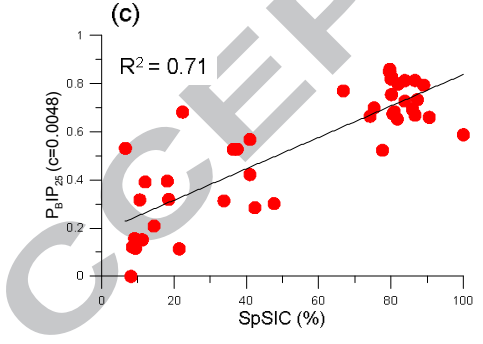

(d)

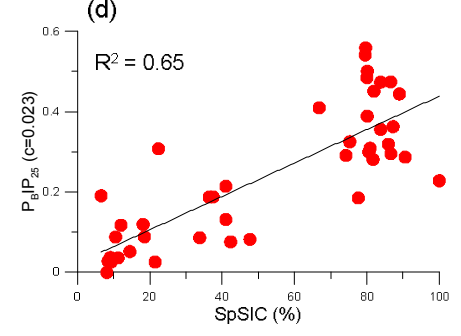

(e)

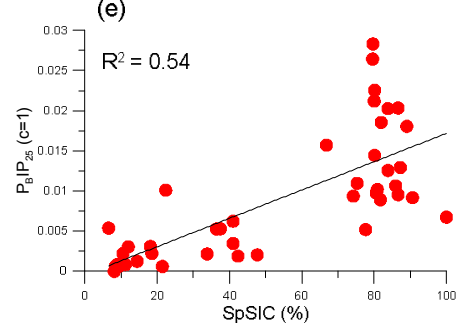


Disclaimer: This is a pre-publication version. Readers are recommended to consult the full published version for accuracy and citation.

Figure 5
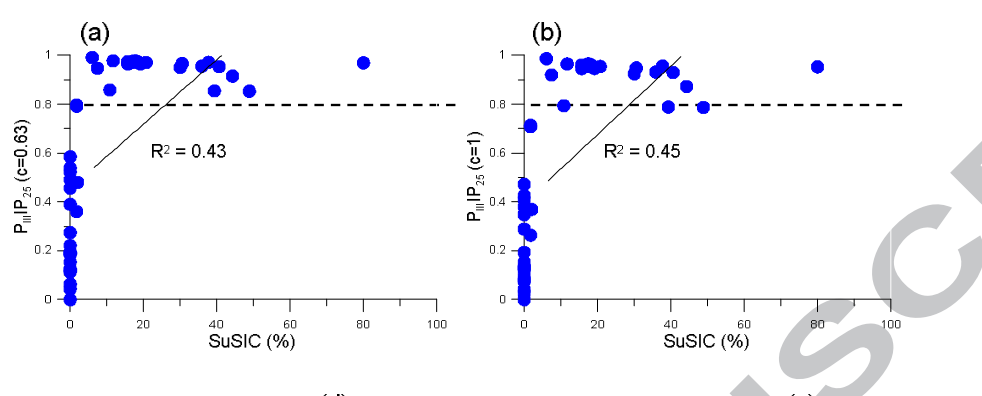

(c)

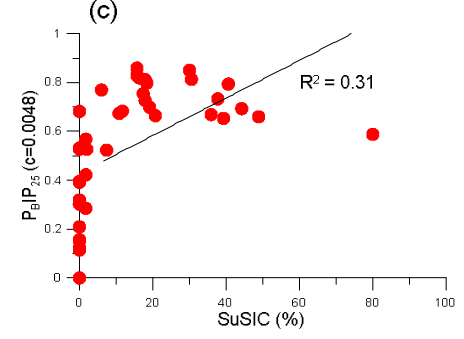

(d)
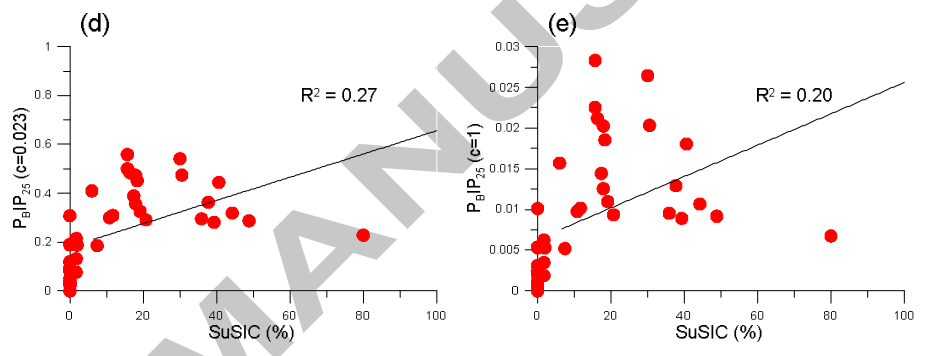
Disclaimer: This is a pre-publication version. Readers are recommended to consult the full published version for accuracy and citation.

Figure 6
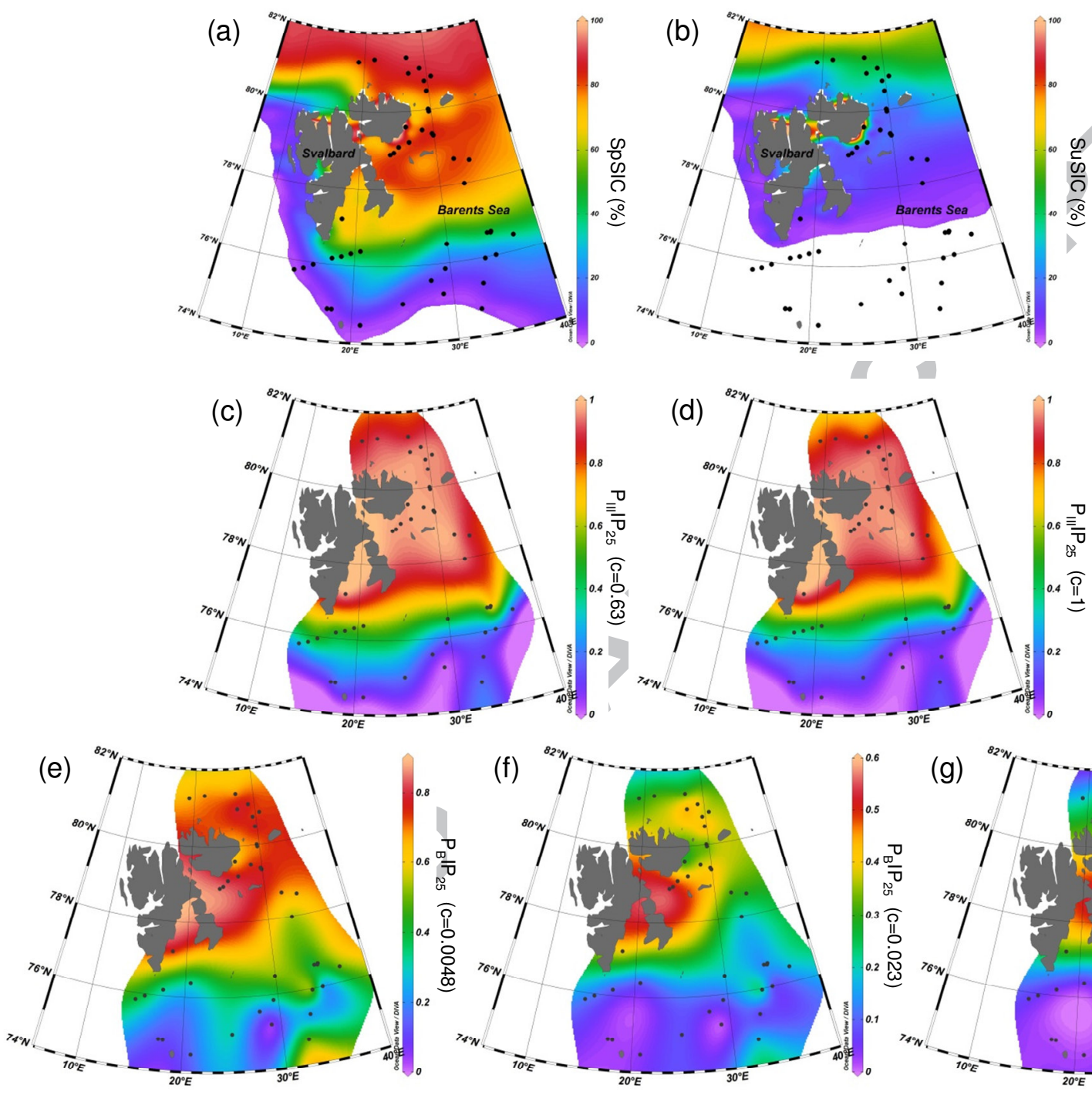

(f)

(f)

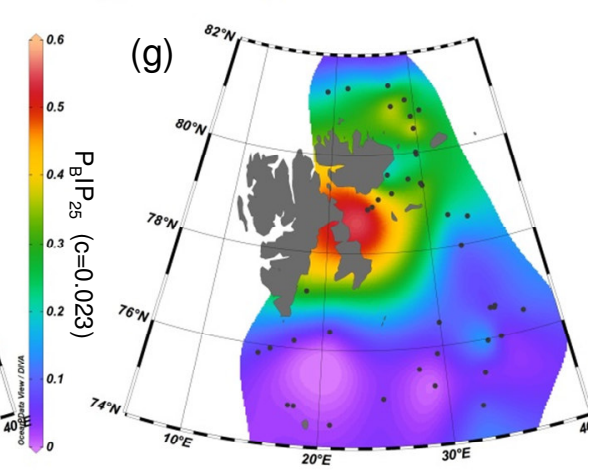


Disclaimer: This is a pre-publication version. Readers are recommended to consult the full published version for accuracy and citation.

\section{Highlights}

-Lipid distributions in Barents Sea sediments compared to sea ice concentration (SIC).

-Lipids are 2 highly branched isoprenoid alkenes (IP ${ }_{25}$ and HBI III) and brassicasterol.

- Good linear relationship between $\mathrm{PIP}_{25}$ and spring SIC but not summer SIC.

-Relationship of $\mathrm{P}_{\mathrm{III}} \mathrm{IP}_{25}$ to SIC less dependent on the balance factor $c$ than $\mathrm{P}_{\mathrm{B}} \mathrm{IP}_{25}$.

-Threshold value for $\mathrm{P}_{\mathrm{III}} \mathrm{IP}_{25}(0.8)$ may be useful proxy for summer sea ice occurrence. 